\title{
Multitrait response to selection in Lolium perenne L. (perennial ryegrass) populations
}

\author{
M. O. HUMPHREYS \\ Institute of Grassland and Environmental Research, Plas Gogerddan, Aberystwyth, Dyfed SY23 3EB, U.K.
}

\begin{abstract}
Genetic variation for growth, quality and persistency characteristics was assessed in six breeding populations of perennial ryegrass. Response to multitrait selection was predicted in each population using a selection index based on 10 traits. Predicted response was compared with that observed after one generation of half-sib family selection based on breeder's preference. There was generally good agreement between predicted and observed response and it was possible to use predictions to identify populations with good potential to meet breeding objectives. For two of the breeding populations, observed selection responses after three generations of recurrent selection and in the progeny of survivors from cut and grazed plots were used to estimate selection pressures on individual traits. It appears that greater selection pressures are imposed on heading date and summer regrowth under grazing compared with cutting managements. The results illustrate the value of a multivariate approach in predicting the progress of breeding programmes and in identifying traits most affected by natural selection pressures.
\end{abstract}

Keywords: half-sib families, heritability, Lolium perenne, recurrent selection, selection index, selection response.

\section{Introduction}

Both the artificial selection imposed by plant and animal breeders and the natural selection studied by evolutionary biologists act on overall phenotypes. Selection often causes changes in complex suites of inter-related traits rather than in isolated component characteristics. Therefore, in order either to predict the consequences of future selection or to ascertain past selection pressures it is necessary to adopt a multitrait approach (see review by Lande, 1988).

Multivariate selection models were first developed in a plant and animal breeding context by Smith (1936) and Hazel (1943) to produce selection indices. Variations of these models were later developed to meet the specific requirements of breeding programmes (Baker, 1986). Lande \& Arnold (1983) used similar approaches to study the manifold effects of natural selection and to identify primary targets of phenotypic selection. All the methods used are based on phenotypic and genetic variance-covariance matrices $(\mathbf{P}$ and $\mathbf{G}$ matrices). These are used to estimate the relative weights $(\mathbf{b})$ placed on individual traits during selection.

In the basic Smith-Hazel optimum index equation, the vector $b$ is estimated from the equation:

$\mathbf{b}=\mathbf{P}^{-1} \mathbf{G}$, where $\mathbf{v}$ is a vector indicating the relative value of traits in the overall economic improvement of plants or animals in breeding programmes. Equation 1 has the same form as the selection response equation:

$\mathbf{r}=\mathbf{P}^{-1} \mathbf{G s}$,

where $\mathbf{r}$ is a vector of selection responses and $\mathbf{s}$ is a vector of selection differentials for measured traits. This is a multivariate extension of the standard univariate selection response equation:

$R=h^{2} S$ (Falconer, 1989, pp. 188-192),

where $R$ is the response to selection, $S$ is the selection differential and $h^{2}$ is the heritability $\left(\sigma_{\mathrm{g}}^{2} / \sigma_{\mathrm{p}}^{2}\right)$ of the trait.

Lande $(1979,1988)$ equates $\mathbf{P}^{-1} \mathbf{s}$ in eqn 2 to $\boldsymbol{\beta}$, which is a vector of partial regression coefficients of relative fitness on the measured traits (the selection gradient), to give the evolutionary equation:

$\Delta \mathbf{z}=\mathbf{G} \boldsymbol{\beta}$,

where $\Delta \mathbf{z}$ is the change in mean phenotype caused by one generation of selection (selection response). The elements of the selection gradient vector $\beta$ are equivalent to the coefficients of the retrospective selection index discussed by Yamada (1977). As from (2)

$\mathbf{P}^{-1} \mathbf{S}=\mathbf{G}^{-1} \mathbf{r}$ 
$\boldsymbol{\beta}$ is also equivalent to the vector of 'desired gains' index coefficients (b) of Pesek \& Baker $(1969,1970)$ where

$$
\mathbf{b}=\mathbf{G}^{-1} \mathbf{h}
$$

and $\mathbf{h}$ is a vector of desired genetic gains. As Pesek \& Baker (1969) point out, $\mathbf{h}$ is equivalent to the vector of genetic response expected from index selection when $\mathbf{b}$ is the solution of the original optimum selection index eqn 1.

The work described in the present paper uses the above selection index equations in two ways. Firstly, they are used in a predictive way to indicate the responses expected for one generation of multitrait selection in populations of perennial ryegrass forming part of a breeding programme. Clearly this is of interest to plant breeders who wish to identify populations in which breeding objectives can be achieved in the most efficient and effective way. Thus response to selection must be consistent with the broad aims of perennial ryegrass improvement (Wilkins, 1991) to combine reliable dry matter production with good nutritive value, tolerance of climatic stress and disease resistance. A vector of index weights $(\mathbf{b})$ was obtained, using eqn 1 , for a range of traits considered important in breeding perennial ryegrass (Lolium perenne L.), including information from both plot and spaced plant trials. Using these weights genetic gains were predicted for one generation of selection from the regression of trait genetic value against genotype index value (Cunningham, 1969, pp. 213-214) and were compared with those gains obtained in practice during one generation of a breeding programme. Charmet \& Grand-Ravel (1991) and Charmet et al. (1993) discussed the use of selection indices for the prediction of genetic gains in grass breeding programmes. However, their indices were based only on spaced plant scores without including information from plots, and observed responses were not presented for comparison with those predicted.

The second use of an index approach is to view selection in a retrospective way. Pesek \& Baker's $(1969,1970)$ :desired genetic gains index eqn 4 was used to determine the weights (b) placed on traits over one generation of selection. Observed responses to selection in two perennial ryegrass populations were measured after natural selection in plot trials subjected to cutting, trampling and grazing pressures. As pointed out earlier, the vector of weights (b) calulated in this way is equivalent to Lande's (1979) selection gradient $\boldsymbol{\beta}$. This approach is of value when selection differentials are not easily measured, as with natural selection, or in breeding programmes where selection based on breeder's judgement of overall merit is not clearly defined in terms of individual traits. For comparison, response to selection was also measured after three generations of artificial selection in a breeding programme.

\section{Materials and methods}

Half-sib families were obtained from six polycrosses based on hybrids between the early heading cultivar Aurora and five late heading cultivars (Majestic, Melle, Perma, S.23 and Ba9795) plus a late heading selection out of Aurora. Further details concerning the origin of this material are given in Humphreys (1989a).

Plots $(1 \mathrm{~m} \times 2 \mathrm{~m})$ of individual half-sib polycross families and the parent cultivars were sown in a fully randomized trial, with two replicates, in September 1982 at a rate of $30 \mathrm{~kg} \mathrm{ha}^{-1}$. The Majestic, Melle, Perma, S.23, Ba9795 and Aurora selection polycrosses provided 31, 30, 24, 17, 19 and 14 families, respectively. Plots were cut eight times in 1983 (13 April, 3 May, 26 May, 16 June, 5 July, 3 August, 1 September and 20 October) and five times in 1984 (25 April, 30 May, 3 July, 21 August and 11 October) at a height of 4 $\mathrm{cm}$ using a Haldrup plot-harvester. Fertilizer was applied after each cut to give a total of $450: 270: 270 \mathrm{~kg}$ $\mathrm{ha}^{-1} \mathrm{~N}, \mathrm{P}_{2} \mathrm{O}_{5}$ and $\mathrm{K}_{2} \mathrm{O}$, respectively, in 1983 and $250: 125: 125 \mathrm{~kg} \mathrm{ha}^{-1}$ in 1984. Samples from each plot were taken at each cut for chemical analysis as described in Humphreys (1989b).

Analysis of water-soluble carbohydrate content (WSC) was carried out using the automated procedure of Thomas (1977) and dry matter digestibility (DMD) was determined using a two-stage enzyme digestion technique (Jones \& Hayward, 1975). Scores for disease damage (mainly crown rust, Puccinia coronata) were recorded on a 1 (slight) to 9 (severe) scale in October 1983 and in August and October 1984. Persistency (ground cover) was scored on a 1 (low) to 5 (high) scale in January 1985 and winter damage was scored in February 1985 on a 1 (low) to 9 (high) scale.

The same half-sib families and parent cultivars were also grown in randomized family rows of 10 plants at $0.6 \mathrm{~m}$ spacings with two replicates. Heading date (day of emergence of the third ear) was recorded during April-June 1983. Plants were then cut back, regrowth scored on a 1 (low) to 9 (high) scale in July 1983 and aftermath heading scored on a 1 (low) to 5 (high) scale in August. Disease scores (mainly crown rust) were recorded as above in August and September. Family row means were used for data analysis.

\section{Selection experiment 1}

Based on yield and quality data from half-sib family plot and spaced plant trials, plants were obtained from 
$5,10,10,8,9$ and 5 families selected from the Majestic, Melle, Perma, S.23, Ba9795 and Aurora polycrosses, respectively. Family selection was carried out according to breeder's preference, without the use of a formal selection index. Each group of selected plants formed the basis of a separate polycross and seed was produced in isolation.

Progeny from the polycrosses were sown in family plots at a rate of $30 \mathrm{~kg} \mathrm{ha}^{-1}$ in a completely randomized design together with the original parent cultivars. After two preliminary cuts in 1984, plots were harvested eight times in 1985 (17 April, 8 May, 6 June, 26 June, 23 July, 22 August, 23 September and 2 October) and five times in 1986 (9 April, 19 May, 27 June, 11 August and 22 September) at a height of $4 \mathrm{~cm}$ using a Haldrup plot-harvester. Fertilizer was applied after each cut to give a total of $460: 260: 260 \mathrm{~kg} \mathrm{ha}^{-1} \mathrm{~N}$, $\mathrm{P}_{2} \mathrm{O}_{5}$ and $\mathrm{K}_{2} \mathrm{O}$ in 1985 and $250: 125: 125 \mathrm{~kg} \mathrm{ha}^{-1}$ in 1986. Samples from each plot were taken at each cut for chemical analysis. Disease (mainly crown rust) was scored in August 1984 as above. Winter damage was recorded on a 1 (low) to 9 (high) scale in February 1985 and ground cover (percentage) was recorded using a reflectance ratio meter (King et al., 1986) in March 1986.

Spaced plants (family rows at $0.6 \mathrm{~m}$ spacing) were raised only from material derived from the crosses with Melle and Perma and for the late heading selection out of Aurora. Heading dates were recorded on these plants in 1985.

\section{Selection experiment 2}

Following the five cuts in 1984, the original half-sib family plot trial was regularly mown to $3 \mathrm{~cm}$ during 1985. Each $1 \mathrm{~m} \times 2 \mathrm{~m}$ plot was split and half was also subjected to regular simulated sheep trampling treatment during 1985 using a purpose built wear machine (Humphreys 1981, 1987). In October 1985, samples of surviving plants derived from the crosses involving Melle and Perma were removed from the plots (at least 30 plants were taken from each treatment for each cross) and used to provide seed in six isolations in 1986.

Samples from the original half-sib families (bulked with each cross) were also sown in September 1982, at $30 \mathrm{~kg} \mathrm{ha}^{-1}$, in $2 \mathrm{~m} \times 2 \mathrm{~m}$ plots replicated four times and randomized. During 1983, 1984 and 1985 they were rotationally grazed with sheep from April to October on nine occasions in each year. As with the cut plots, surviving plants (at least 30) were removed in October 1985 and used to produce seed in 1986.

The progeny of survivors from three treatments (cut-unworn, cut-worn and grazed) were sown in plots in 1989. Also included in the trial were selection lines, derived from the Melle and Perma crosses after three generations of recurrent multitrait selection based on breeder's preference, together with the original parent cultivars. After three preliminary cuts in 1989 , the plots were cut eight times in 1990 (6 April, 1 May, 24 May, 14 June, 11 July, 21 August, 19 September and 5 October) and five times in 1991 (14 April, 4 June, 16 July, 21 August and 30 September). Samples were taken for chemical analysis as in other plot trials. Regrowth on a 1 (poor) to 9 (good) scale was recorded in June 1991 as was ground cover using a reflectance ratio meter.

Spaced plants of the same material were planted in randomized and replicated family rows in May 1987 at $0.6 \mathrm{~m}$ spacing. Disease infection (mainly crown rust) was scored on a 1 (low) to 9 (high) scale in October 1987. Heading date was recorded during April-June 1988 and plants were cut back to $10 \mathrm{~cm}$. Summer regrowth was scored on spaced plants in July 1988.

\section{Statistical analysis}

In both plot and spaced plant trials the significance of differences between half-sib families for individual traits was tested using analyses of variance. Multivariate analysis of variance was used to compute phenotypic and genetic covariance between traits. These were used in the standard Smith-Hazel selection index equation:

$\mathbf{P b}=\mathbf{G v}$,

where $\mathbf{P}$ is a variance/covariance matrix of phenotypic measurements and $\mathbf{b}$ is a vector of selection weights for measured traits. $\mathbf{G}$ is the genetic variance/covariance matrix describing genetic relationships among measured traits and a set of basic economic traits which are weighted by values contained in vector $\mathbf{v}$. Selection index weights for measured traits were found from the equation:

$\mathbf{b}=\mathbf{P}^{-1} \mathbf{G v}$.

In selection experiment 1 , the change produced in each individual trait as a result of selection on the index was calculated from the regression of genetic value for the trait against genotype index value (Cunningham, 1969), i.e.

$b_{Y_{i I}}=\operatorname{cov}_{\left(Y_{i I}\right)} / \sigma_{I}^{2}$

where $\operatorname{cov}_{\left\langle Y_{i l}\right)}$ is the covariance between $Y_{i}$, the additive genetic value for the $i$ th trait, and $I$, the index value; and $\sigma_{I}^{2}$ is the variance of the selection index which equals $\mathbf{b}^{\prime} \mathbf{P b}$. This is the $i$ th element in the vector $\mathbf{b}^{\prime} \mathbf{G} / \sigma_{I}^{2}$ which gives the change in genetic value expected for 
each trait after unit change in index value. One round of selection on the index produces $D \sigma_{I}$ units of change in the index and thus the vector $D \sigma_{I}\left(\mathbf{b}^{\prime} \mathbf{G} / \sigma_{I}^{2}\right)$ describes units of change for each trait (where $D$ is the intensity of selection on a standardized normal distribution).

The standard error attached to this regression may be calculated as:

$$
D \sqrt{\operatorname{Var}\left(Y_{i}\right)-\left(\mathbf{b}^{\prime} \mathbf{G} \cdot \mathbf{b}^{\prime} \mathbf{G} / \sigma_{I}^{2}\right)} .
$$

In selection experiment 2 , the index weights which must be applied to the measured traits to produce the observed selection response were calculated as:

$\mathbf{b}=\mathbf{G}^{-1} \mathbf{h} \sigma_{I} / D$

where $\mathbf{h}$ is a vector of observed selection responses and $D$ and $\sigma_{I}$ are as defined above.

\section{Results and discussion}

Analyses of variance were carried out on data for all measurements made in the original plot and spaced plant half-sib family trials in 1983 and 1984 to determine whether significant variation existed between families and to calculate among-family heritabilities (Table 1). Average heritabilities of at least 0.3 were obtained for the following seven traits derived from plot data.

SPG Spring growth comprising cuts 1 and 2 in 1983.

LTSM Late summer growth comprising cuts 6, 7 and 8 in 1983.
WSC1 Water-soluble carbohydrate content averaged over cuts 5, 6,7 and 8 in 1983 (i.e. in nonreproductive growth).

WSC2 Water-soluble carbohydrate content averaged over all 5 cuts in 1984 .

DMD Digestibility of cuts $1-5$ in 1983 and cuts 1-2 in 1984.

DIS Disease score averaged over October 1983 and 1984.

WINTD Winter damage score recorded in February 1985.

These were included in a selection index together with total yield (TY) over all 13 harvests in 1984 and 1985 which was included for completeness despite generally low family heritabilities. In addition, heading date (HD) and summer regrowth (REG) in 1983 were included from spaced plant data.

\section{Selection experiment 1}

The economic weights attached to the 10 traits in the index were equal in terms of phenotypic standard deviation units which allowed for differences in scale of measurement (see Bradshaw, 1987), although direction of desired gain (positive or negative) was also indicated. Selection intensities, calculated from the proportion of families selected within a polycross, were $1.46,1.06$, $0.91,0.81,0.81$ and 0.99 for the Majestic, Melle, Perma, S.23, Ba9795 and Aurora polycrosses, respectively. The selection responses expected in the 10 traits listed above after one generation of multitrait selection

Table 1 Significance levels of variation among half-sib families and family heritabilities $\left(h^{2}\right)$ for traits used to measure response to selection in Lolium perenne

\begin{tabular}{|c|c|c|c|c|c|c|c|c|c|c|c|c|}
\hline & \multicolumn{2}{|c|}{$\begin{array}{r}\text { Aurora } \times \\
\text { Majestic }\end{array}$} & \multicolumn{2}{|c|}{$\begin{array}{c}\text { Aurora } \times \\
\text { Melle }\end{array}$} & \multicolumn{2}{|c|}{$\begin{array}{c}\text { Aurora } \times \\
\text { Perma }\end{array}$} & \multicolumn{2}{|c|}{$\begin{array}{c}\text { Aurora } \times \\
\text { S.23 }\end{array}$} & \multicolumn{2}{|c|}{$\begin{array}{c}\text { Aurora } \times \\
\text { Ba9795 }\end{array}$} & \multicolumn{2}{|c|}{$\begin{array}{c}\text { Aurora } \\
\text { Selection }\end{array}$} \\
\hline & $P$ & $h^{2}$ & $P$ & $h^{2}$ & $P$ & $h^{2}$ & $P$ & $h^{2}$ & $P$ & $h^{2}$ & $P$ & $h^{2}$ \\
\hline \multicolumn{13}{|l|}{ Plots } \\
\hline SPG & $(*)$ & 0.28 & $*$ & 0.35 & $*$ & 0.37 & NS & 0.00 & $*$ & 0.47 & $*$ & 0.46 \\
\hline LTSM & NS & 0.08 & $(*)$ & 0.24 & $*$ & 0.45 & NS & 0.23 & $(*)$ & 0.28 & $*$ & 0.52 \\
\hline TY & NS & 0.06 & NS & 0.01 & $*$ & 0.35 & $(*)$ & 0.34 & NS & 0.15 & NS & 0.00 \\
\hline WSC 1 & NS & 0.11 & $* *$ & 0.44 & $(*)$ & 0.31 & $*$ & 0.50 & NS & 0.00 & $* *$ & 0.63 \\
\hline WSC2 & $* * *$ & 0.71 & $*$ & 0.34 & $* * *$ & 0.67 & $* * *$ & 0.70 & $* *$ & 0.54 & $*$ & 0.55 \\
\hline DMD & $*$ & 0.32 & NS & 0.14 & $* * *$ & 0.62 & NS & 0.01 & $* *$ & 0.53 & $*$ & 0.48 \\
\hline DIS & $* * *$ & 0.62 & $* *$ & 0.44 & $* *$ & 0.55 & $*$ & 0.41 & $* * *$ & 0.83 & $* * *$ & 0.91 \\
\hline WINTD & $*$ & 0.39 & $* * *$ & 0.60 & NS & 0.01 & $*$ & 0.39 & $*$ & 0.43 & $* * *$ & 0.78 \\
\hline \multicolumn{13}{|c|}{ Spaced plants } \\
\hline HD & NS & 0.16 & NS & 0.07 & $* *$ & 0.48 & NS & 0.00 & $*$ & 0.36 & $* *$ & 0.70 \\
\hline REG & $*$ & 0.40 & $*$ & 0.42 & NS & 0.13 & NS & 0.21 & NS & 0.10 & NS & 0.21 \\
\hline
\end{tabular}


are given in Table 2 together with their standard errors. Also shown in Table 2 are the selection responses observed for one generation of family selection in experiment 1 . All changes, predicted and observed, are expressed as percentages of mid-parent values for each trial. Summer regrowth was not measured in experiment 1 and heading date was only recorded for the crosses with Melle and Perma and the Aurora selection.

Although theoretical and simulated expectations for multitrait selection response have been published (Tai, 1986; Charmet \& Grand Ravel, 1991; Charmet et al., 1993), there has been little discussion in the literature on responses obtained in practice. Generally, there was good correspondence between predicted and observed selection responses both in direction and magnitude although some exceptions were apparent among the different breeding populations. The population based on the cross with Melle showed the best overall correspondence between breeding objectives and predicted/ observed selection response. Improved growth in spring and summer was combined with an increase in
WSC, an important nutritive value trait (Humphreys, $1989 \mathrm{~b}$ ), and a large reduction in disease susceptibility and winter damage. Compared with this, response in the other populations all showed some deficiencies. For example, in the late heading selection from Aurora, although disease susceptibility was reduced, the amount of winter damage increased. The population based on the cross with Perma showed a reasonable combination of selection responses except that there was some discrepancy between predicted and observed values for some traits such as disease resistance.

\section{Selection experiment 2}

The index weights required to produce the observed responses to the selection pressures imposed by the various plot treatments were calculated from the equation:

$\mathbf{b}=\mathbf{G}^{-1} \mathbf{h} \sigma_{t} / D$.

These were multiplied by the trait means over all six populations included in the original half-sib family

Table 2 Observed selection response in Lolium perenne after one generation of family selection (obs) and that predicted from multivariate index selection (MPd \pm standard error)

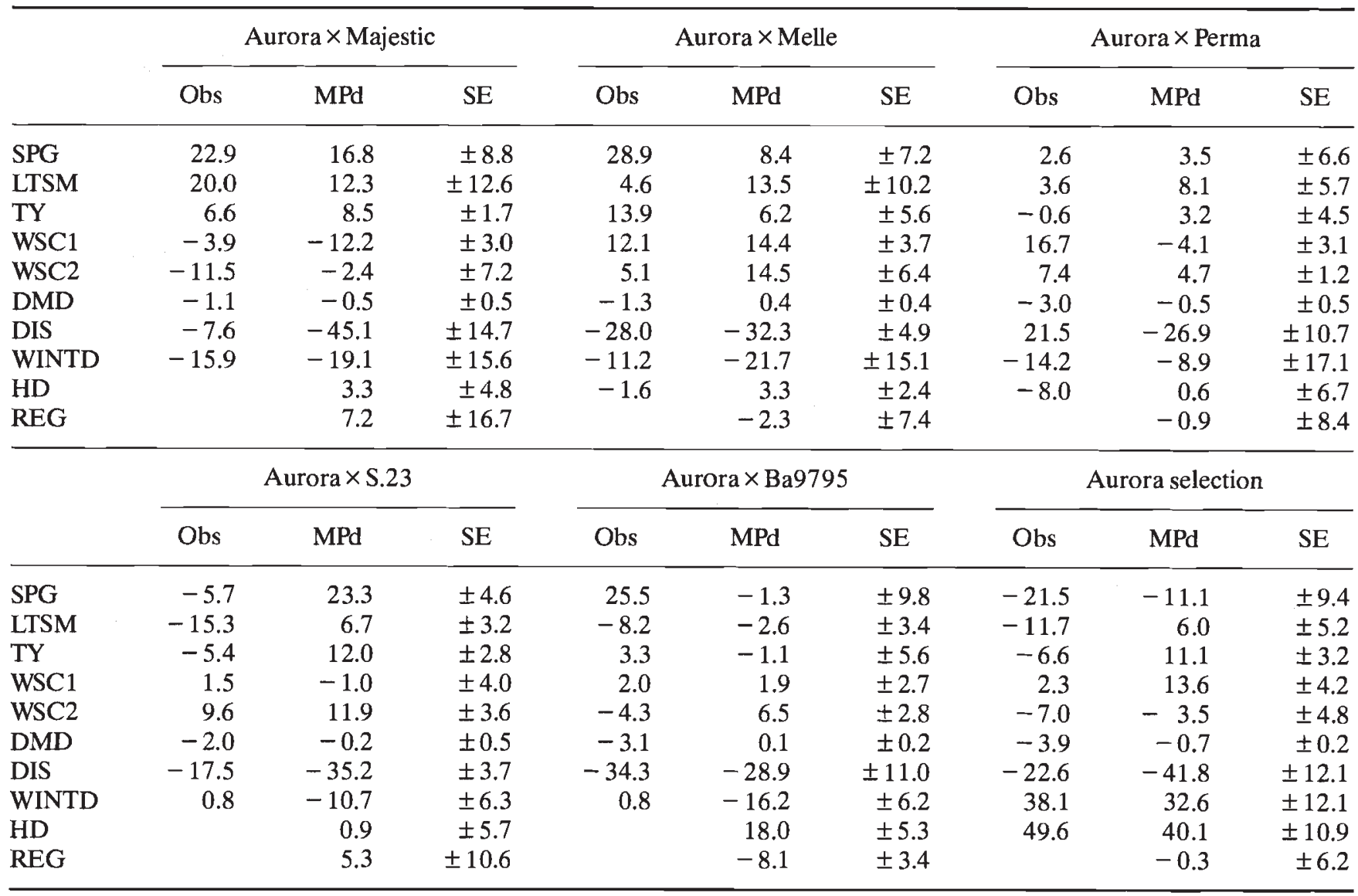


Table 3 Standardized index score components for survivors of plot treatments and a breeding line derived from a cross between Aurora and Melle cultivars of Lolium perenne

\begin{tabular}{lrrrrr}
\hline & Cut & Cut-worn & Grazed & Bred & Mean \\
\hline SPG & 5.2 & 4.7 & 4.2 & 7.3 & 5.3 \\
LTSM & -7.6 & -8.4 & -4.8 & -7.4 & -7.0 \\
TY & -2.2 & -2.8 & -2.4 & -7.5 & -3.7 \\
WSC1 & 2.0 & 1.7 & -0.4 & 4.0 & 1.8 \\
WSC2 & 6.1 & 3.5 & 3.0 & 7.1 & 5.0 \\
DMD & 27.0 & 8.8 & 46.0 & -5.7 & 19.0 \\
DIS & 9.7 & 8.9 & 10.3 & 8.6 & 9.4 \\
HD & 0.0 & -1.2 & 2.6 & 6.6 & 2.0 \\
REG & 0.9 & 0.8 & 1.0 & -0.9 & 0.5 \\
Index score & 40.2 & 14.3 & 58.5 & 11.7 & 31.2 \\
SE & 2.7 & 2.8 & 2.8 & 3.7 & \\
\hline
\end{tabular}

Table 4 Standardized index score components for survivors of plot treatments and a breeding line derived from a cross between Aurora and Perma cultivars of Lolium perenne

\begin{tabular}{lrrrrr}
\hline & Cut & Cut-worn & Grazed & \multicolumn{1}{c}{ Bred } & \multicolumn{1}{c}{ Mean } \\
\hline SPG & 4.1 & 1.9 & -0.1 & -0.5 & 1.3 \\
LTSM & -12.2 & -9.8 & -9.5 & -12.6 & -11.0 \\
TY & 15.4 & 14.9 & 18.2 & 13.7 & 15.6 \\
WSC1 & 11.8 & 15.8 & 11.1 & 10.7 & 12.3 \\
WSC2 & -28.8 & -27.5 & -25.4 & -18.0 & -24.9 \\
DMD & 223.6 & 199.4 & 175.9 & 158.0 & 189.2 \\
DIS & 0.4 & 0.5 & 2.0 & 0.2 & 0.7 \\
HD & 0.2 & 3.1 & 7.1 & 0.5 & 2.7 \\
REG & -4.4 & -3.4 & 1.9 & -8.1 & -3.5 \\
Index score & 209.5 & 194.5 & 180.4 & 143.9 & 182.1 \\
SE & 3.5 & 3.5 & 2.5 & 2.6 & \\
\hline & & & & &
\end{tabular}

trials to allow comparisons to be made irrespective of scales of measurement and trait means for individual populations. These mean index score components together with the overall index values and their standard errors for each of the treatments are given in Tables 3 and 4 for the crosses with Melle and Perma, respectively. Strictly, the retrospective index weights should only be derived from one generation of selection. Calculations based on longer periods of selection must assume that the genetic covariance matrix $\mathbf{G}$ remains constant over generations which may or may not be correct (Turelli, 1988; Wilkinson et al., 1990). In the present case it is considered that changes in $\mathbf{G}$ are unlikely to be large over just three generations of selection and that the weights calculated from the response obtained in the breeding programme provide interesting comparisons with those obtained from plot survivors.
In the population based on the cross with Melle the weights necessary to achieve the observed responses to artificial selection were higher than those calculated for plot survivors with regard to SPG, WSC1, WSC2 and HD, but lower for DIS. This reflects breeding objectives, i.e. good spring growth in later heading material combined with a high WSC content and good disease resistance (see Humphreys, 1984), and confirms the potential of this population which was indicated in the first selection experiment. From the response to different managements observed in the Melle-based population, it appears that trampling/grazing pressures place less selective importance on WSC than in the breeding programme. For both WSC1 and WSC2, selection weights were higher in the cut-unworn treatment than in the cut-worn treatment. Weights for increased WSC were also higher under cutting than under grazing. Greater weight was also placed on LTSM, HD and REG in the grazed plots than in the cut plots which may reflect the importance of these traits in maintaining perenniality under grazing. Shifts towards later heading dates have been observed previously in survivor populations from intensively grazed leys (Charles, 1970, 1973). Tyler (1988) also demonstrated that the progeny of perennial ryegrass plants collected along a path were considerably later heading than those from the surrounding hay meadow.

In the population based on the cross with Perma there is no clear indication of breeding objectives from the weights derived from response to artificial selection. This may not be suprising given the lack of agreement between predicted and observed response shown in the first selection experiment. A number of factors may inflate the theoretical errors attached to index estimation (Hayes \& Hill, 1980). For example: (1) genetic variation may be released by recombination over generations of selection; (2) selection alone will tend to decrease genetic variance (Charmet et al., 1993); (3) the influence of nonadditive genetic effects (dominance and epistasis) may change; (4) genetic correlation between traits may change if they are based on linkage relationships and will tend to zero as genetic variances decline; (5) genotype $\times$ environment interactions may disguise the genetic variation exposed to selection; and (6) selection pressures may vary.

In general the population based on the Perma cross contained more genetic variability than that based on the cross with Melle. Over generations of selection it is possible that response to breeding objectives may become obscured by changes in genetic covariance. Weights calculated for changes in DMD were very high in the Perma-based population which also showed a high heritability for DMD. Thus large changes in DMD may have affected the response in associated traits such as WSC and DIS. However, as in the Melle-based 
population, the weight on DIS was lower and that for WSC2 was higher in the bred material than in the survivor populations which reflects breeding aims and the potential predicted in the first selection experiment.

The response to different managements shown by the Perma-based population indicates that the selection weights on traits in the cut-worn treatment and the cutunworn treatment were similar, although SPG tended to have a lower weight and LTSM, REG and HD tended to have a higher weight in the latter treatment. These trends were reinforced in the grazed plot survivors especially with regard to heading date. Again this suggests that these traits have importance in surviving trampling-grazing pressures. Thus grazed plot survivors may be of value in improving persistency in perennial ryegrass breeding programmes. However, it may be more fruitful to impose artificial selection on those traits which are weighted heavily in response to grazing pressures, such as good regrowth, good late summer growth and a late heading date.

\section{Conclusions}

Despite various possible sources of error, there was generally good agreement between predicted multitrait selection response and that observed after one generation of selection among half-sib families in six populations of perennial ryegrass. From the responses predicted it was possible to identify the populations in which breeding objectives were most likely to be achieved. In particular, the population based on the cross with Melle showed a good balance of response in growth, quality and persistency traits. The potential of this population was also evident after three generations of selection and it was used to form the basis of the registered variety Cariad (see Radojevic et al., 1994).

It also proved possible to identify traits of importance in surviving the selection pressures generated by the three plot managements (cut-worn, cut-unworn and grazed). This confirms previous work in indicating that selection pressures on traits such as heading date and summer regrowth are more severe under grazing than under cutting. Thus multivariate approaches can be of value in predicting breeding progress and in identifying those traits most affected by natural selection pressures.

\section{Acknowledgements}

Markku Farrell is thanked for excellent technical assistance and Dr D. I. H. Jones is thanked for providing facilities for chemical analysis. Computations were carried out on the IGER MicroVAX 3600, using GENSTAT 5 programs. The breeding work was carried out with the financial support of MAFF.

\section{References}

BAKER, R. 1986. Selection Indices in Plant Breeding, pp. 1-12. CRC Press, Boca Raton, FL.

BRADSHAW, J. E. 1987. The choice of selection index in kale (Brassica oleracea L.) population improvement. Theor. Appl. Genet., 75, 165-169.

CHARLES, A. H. 1970. Ryegrass populations from intensively managed leys. I. Seedling and spaced plant characters. $J$. Agric. Sci. Camb., 75, 103-107.

CHARLES, A. H. 1973. A comparison of ryegrass populations from intensively managed permanent pastures and leys. $J$. Agric. Sci. Camb., 81, 99-106.

CHARMET, G. AND GRAND-RAVEL, C. 1991. Expected response to selection in synthetic populations of perennial ryegrass. $P l$. Breed., 107, 148-155.

CHARMET, F., RAVEL, C. AND BALFOURIER, F. 1993. Change of expected response to multitrait selection in a synthetic population of perennial ryegrass through recurrent selection. I. Prediction of the Bulmer effect. Pl. Breed., 111, 227-235.

Cunningham, E. P. 1969. Animal Breeding Theory. Institute of Animal Genetics and Breeding, Agricultural College of Norway. Landbruksbokhandelen/Universitetsforlaget, Vollebekk/Oslo.

FALCONER, D. S. 1989. Introduction to Quantitative Genetics., 3rd edn. Longman, Harlow, Essex.

HAYES, J. F. AND HILL, W. G. 1980. A reparameterization of a genetic selection index to locate its sampling properties. Biometrics, 36, 237-248.

HAZEL, L. N. 1943. The genetic basis for constructing selection indexes. Genetics, 28, 476-490.

HUMPHREYS, M. O. 1981. Effect of wear on cultivars and selections of Lolium perenne at two sites. J. Sports Turf Res. Inst., 57, 55-64.

HUMPHREYS, M. o. 1984. Breeding for seasonal consistency in perennial ryegrass for pastures. In: Simon, U. (ed.) Proceedings of the Eucarpia Fodder Crops Section Meeting 1984, pp. 57-70. Lehrstuhl für Grünland und Futterbau der Technischen Universität München, FreisingWeihenstephan.

HUMPHREYS, M. O. 1987. Grass breeding objectives for AD2000. In: Hardcastle, J. (ed.) Science and Better Use of Grassland, pp. 2-3. AFRC, London.

HUMPHREYS, M. O. 1989a. Water-soluble carbohydrates in perennial ryegrass breeding. I. Genetic differences among cultivars and hybrid progeny grown as spaced plants. Grass Forage Sci., 44, 231-236.

HUMPHREYS, M. O. $1989 \mathrm{~b}$. Water-soluble carbohydrates in perennial ryegrass breeding. II. Cultivar and hybrid performance in cut plots. Grass Forage Sci., 44, 237-244.

JONES, D. I. H. AND HAYWARD, M. V. 1975. The effect of pepsin pretreatment of herbage on the prediction of dry matter digestibility from solubility in fungal cellulase solutions. $J$. Sci. Food Agric., 26, 711-718.

KING, J., SIM, E. M. AND BARTHRAM, G. T. 1986. A comparison of spectral reflectance and sward surface height measurements to estimate herbage mass and leaf area index in continuously stocked ryegrass pastures. Grass Forage Sci., 41, 251-258.

(c) The Genetical Society of Great Britain, Heredity, 74, 510-517. 
LANDE, R. 1979. Quantitative genetic analysis of multivariate evolution, applied to brain:body size allometry. Evolution, 33, 402-416.

LANDE, R. 1988. Quantitative genetics and evolutionary theory. In: Weir, B. S. , Eisen, E. J. , Goodman, M. M. and Namkoong, G. (eds) Proceedings of the Second International Conference on Quantitative Genetics, pp. 71-84. Sinauer Associates, Sunderland, MA.

LANDE, R. AND ARNOLD, s. J. 1983. The measurement of selection on correlated characters. Evolution, 37, 1210-1226.

PESEK, J. AND BAKER, R. J. 1969. Desired improvement in relation to selection indices. Can. J. Plant Sci., 49, 803-804.

PESEK, J. AND BAKER, R. J. 1970. An application of index selection to the improvement of self-pollinated species. Can. J. Plant Sci., 50, 267-276.

RADOJEVIC, I., SIMPSON, R. J., St. JOHN, J. A. AND HUMPHREYS, M. O. 1994. Chemical composition and in vitro digestibility of lines of Lolium perenne selected for high concentrations of water soluble carbohydrate. Aust. J. Agric. Res., 45, 901-912.
SMITH, H. F. 1936. A discriminant function for plant selection. Ann. Eugen., 7, 240-250.

TAI, G. C. C. 1986 . A method to construct confidence interval for expected response to multi-trait selection. Theor. Appl. Genet., 71, 595-599.

THомаS, т. А. 1977. An automated procedure for the determination of soluble carbohydrates in herbage. J. Sci. Food Agric., 28, 639-642.

TURELLI, M. 1988. Phenotypic evolution, constant covariances and the maintenance of additive variance. Evolution, 42, 1342-1347.

TYLER, B. F. 1988. Description and distribution of natural variation in forage grasses. In: Proceedings of Eucarpia Fodder Crops Section Meeting, Natural Variation and Breeding for Adaptation, pp. 13-22. INRA, Lusignan, France.

WILKINS, P. W. 1991. Breeding perennial ryegrass for agriculture. Euphytica, 52, 201-214.

WILKINSON, G. S., FOWLER, K. AND PARTRIDGE, L. 1990. Resistance of genetic correlation structure to directional selection in Drosophila melanogaster. Evolution, 44, 1990-2003.

YAMADA, Y. 1977. Evaluation of the culling variate used by breeders in actual selection. Genetics, 86, 885-899. 